\title{
PREVALENCE OF DIFFERENT DISEASES BASED ON HISTOPATHOLOGICAL FEATURES IN BIOPSIES FROM PATIENTS IN MALAKAND DIVISION, KHYBER PAKHTUNKHWA
}

\author{
Aurangzeb Khan ${ }^{1}$, Munaza Khattak', Khurrum Saleem ${ }^{3}$, Shifa A Khan ${ }^{4}$, Mahd Aftab Khan ${ }^{5}$ \\ 'Department of Pathology, Swat Medical College, Saidu Sharif Swat - Pakistan \\ ${ }^{2}$ Department of Physiology, Peshawar Medical \& Dental College, Peshawar - Pakistan \\ ${ }^{3}$ Department of Medicine, Medical C Ward Khyber Teaching Hospital, Peshawar - Pakistan \\ ${ }^{4}$ House officer, Kuwait Teaching Hospital, Peshawar - Pakistan \\ ${ }^{5}$ Final Year MBBS Peshawar Medical \& Dental College, Peshawar - Pakistan
}

\begin{abstract}
Introduction: The main objective of this study was to determine the prevalence of different diseases based on histopathological features in biopsies from patients in Swat, Malakand Division, Khyber Pakhtunkhwa.

Material \& Methods: Seventy-three biopsies, as received sequentially in Anwar Clinical Laboratory Swat from 07 January 2019 to 10 April 2019, from different patients who had visited different specialty clinics in public and private hospitals of Saidu Sharif Swat, were reviewed. All the biopsies were reported by trained pathologists and histopathological results were analyzed.

Results: The highest prevalence rate was from diseases belonging to female reproductive system which was $23 \%$, followed by GIT and dental diseases (19\% each), skin diseases (18\%), breast and lymph nodes (07\% each), male reproductive system $(4 \%)$ and Thyroid diseases (3\%). Total carcinoma cases found were 05 with a prevalence rate of $(5 / 73 \times 100=6.89)$ or $07 \%$. The mean age of affected patients was $35.43(+19.21)$ with a peak prevalence in the group between 20 and 39 years. Prevalence gradually decreased after age 40 with a slight surge between 60 and 75 years.
\end{abstract}

Conclusion: The study concluded that biopsies taken for different diseases are more prevalent to female reproductive system and the prevalence of different diseases is low in male as compared to female.

Keywords: Prevalence, Biopsy, Histopathology, Carcinoma.

This article may be cited as: Khan A, Khattak M, Saleem K, Khan SA, Khan MA. Prevalence of different diseases based on Histopathological features in Biopsies from patients in Malakand Division, Khyber Pakhtunkhwa. J Med Sci 2021 January;29(1):26-29

\section{INTRODUCTION}

Histopathology is still regarded as the gold standard/ tool for confirmation of a disease in spite of much sophisticated tests available now adays. Microscopy often puts in a lot of information and it is for this reason that it is more and more performed especially in patients undergoing surgery for various problems ${ }^{1}$. The objective of this study was to determine the prevalence of different diseases based on histopathological features in biopsies

\section{Correspondence}

Dr Aurangzeb Khan

Assistant Professor

Department of Pathology

Swat Medical College, Saidu, Swat- Pakistan

Email: azkhan63@hotmail.com

Cell: +92-333-9123870

Date received: $\quad 24-12-2020$

Date revised: $15-01-2021$

Date accepted: 12-02-2021 taken from patients in Swat, Malakand Division, Khyber Pakhtunkhwa.

\section{MATERIAL AND METHODS}

Malakand Division is an administrative division of the Khyber Pakhtunkhwa of Pakistan. In 1970, Malakand Division was formed from the princely states of Chitral, Dir and Swat (incorporated into West Pakistan in 1969). The total area of Malakand Division is $952 \mathrm{~km}^{2}$ and has a population density of 720,295 as per 2017 census. It comprises of 09 districts. Basically, this is a retrospective study of a population of patients who had visited different specialty clinics in public and private Hospitals of Saidu Sharif Swat and whose biopsies were reported by Anwar Clinical Laboratory Swat from 07 January 2019 to 10 April 2019, Biopsy specimens as received in $10 \%$ buffered formalin, were further fixed in formalin, prepared, stained routinely with hematoxylin and eosin and reported by pathologist. 
Prevalence Of Different Diseases Based On Histopathological Features In Biopsies From Patients In Malakand Division....

The results collected were then evaluated in the Microsoft Office Excel.

\section{RESULTS}

A total of 73 biopsies, 25 from male patients (34.25\%) and 48 (65.75\%) from female patients were analyzed. The average age of the sample patients was 35.43 $( \pm 19.21)$. The average age of male patients was 37.91 years $( \pm 25.26)$, and the average age of women was 33.64 years $( \pm 16.78)$.

The result of the biopsies received, examined and reported are shown in table 2 . Of the 73 samples, only five $(6.88 \%)$ turned out to be malignant. The malignant cases reported were found 02 in GIT $(2 / 14 \times 100=14.29 \%)$, 02 cases were related to dental $(2 / 14 \times 100=14.29 \%)$ and 01 case $(1 / 5 \times 100=20 \%)$ in lymph node. The rest of the biopsies were other non-malignant diseases. The highest number of biopsies were from the female reproductive system followed by GIT and dental diseases. Other were from skin, breast, male reproductive system and thyroid.

The highest prevalence rate was from diseases belonging to female reproductive system which was $23 \%$ followed by GIT and dental diseases (19\% each), skin diseases (18\%), breast and lymph nodes (07\% each), male reproductive system (4\%) and Thyroid diseases (3\%). Total carcinoma cases found were 05 with a prevalence rate of $(5 / 73 \times 100=6.89)$ or $07 \%$. The mean age of infected patients was $35.43(\mathrm{SD}: \pm 19.21)$ with a peak prevalence in the group between 20 and 39 years. Prevalence gradually decreased after age 40 with a slight surge between 60 and 75 years.

Table 1: Distribution of Samples from Patients by Age Group

\begin{tabular}{|c|c|c|c|}
\hline \multirow{2}{*}{$\begin{array}{c}\text { Age in Years } \\
0.33 \text { (04 Months) to } 09\end{array}$} & \multicolumn{2}{|c|}{ Sex } & \multirow[t]{2}{*}{ Total } \\
\hline & Male & Female & \\
\hline 10 to 19 & 03 & 03 & 06 \\
\hline 20 to 29 & 02 & 08 & 10 \\
\hline 20 to 39 & 02 & 07 & 09 \\
\hline 30 to 49 & 05 & 12 & 17 \\
\hline 40 to 59 & 00 & 05 & 05 \\
\hline 50 to & 00 & 05 & 05 \\
\hline 60 to 69 & 04 & 04 & 08 \\
\hline 70 to 79 & 03 & 01 & 04 \\
\hline Age Unknown 09 & 06 & 03 & 09 \\
\hline Total & 25 & 48 & 73 \\
\hline
\end{tabular}

Table 2: Histopathological Findings

\begin{tabular}{|c|c|c|c|c|c|}
\hline S. No & Organ/System affected & Total cases & Male & Female & Malignant Cases \\
\hline 1. & GIT & 14 & 04 & 10 & 02 \\
\hline 2. & Female Reproductive System Breast & 17 & 0 & 17 & 0 \\
\hline 3. & Dental & 05 & 01 & 04 & 0 \\
\hline 4. & Male Rep. Sys. & 14 & 07 & 07 & 02 \\
\hline 5. & Lymph Nodes & 03 & 03 & 0 & 0 \\
\hline 6. & Skin & 05 & 01 & 04 & 01 \\
\hline 7. & thyroid & 13 & 08 & 05 & 0 \\
\hline 8. & & 02 & 0 & 02 & 0 \\
\hline
\end{tabular}

\section{DISCUSSION}

The highest number of biopsies received in our laboratory were for the disorders of the female reproductive system. The disease can involve any one of the many varied reproductive organs; The ovaries, Fallopian tubes, Uterus, Cervix, and Vagina. Disorders of this system often present during the reproductive years either as altered pelvic pain, menstruation, or infertility ${ }^{2}$. These can be both benign or malignant. However malignant diseases often present in the late reproductive or menopausal years. This is unfortunate that by the time the patient seeks medical help, many have already metastasized and have therefore they often had high mortality rates when they are diagnosed ${ }^{1}$. These disorders can also occur secondary to diseases in other organs whose function affects reproductive organs like the brain, hypothalamus, endocrine glands (pi- 
Prevalence Of Different Diseases Based On Histopathological Features In Biopsies From Patients In Malakand Division....

tuitary, thyroid, adrenals) liver and kidney. Typically, these present painlessly. Similarly disorders of the reproductive system can cause disorders in other organs/tissues like osteoporosis (loss of bone mass) due to alterations in the hormones, atherogenesis and alterations in cardiovascular compliance, and an increased risk of some forms of cancer (e.g., endometrial carcinoma as a consequence of estrogen excess and progesterone deficiency) ${ }^{2}$. Among 73 cases studied, highest number of 17 cases (23\%) were related to female reproductive system lesions. Some of them were cystic adenofibroma of ovary with follicular cysts of ovary, decidual tissue endometrium, proliferative phase endometrium, late secretary phase endometrium, menstrual phase endometrium, adenomyosis of uterus, mural leiomyomas (fibroids) and mucinous cyst adenoma.

A wide variety of lesions can occur in Gastrointestinal tract (GIT) especially malignant tumors. About $15-25 \%$ of all malignancies occur in $\mathrm{GIT}^{3}$. Microscopy of the biopsies is basically to provide essential diagnostic and prognostic information for the best clinical management of the patient ${ }^{4,5}$. Amongst 73 cases studied, 14 cases (19\%) were related to $\mathrm{Gl}$ lesions where 02 were polyps (juvenile rectal polyp and adenomatous gastric polyp), 04 were chronic non-specific choleycystitis with cholelithiasis, 01 was peptic ulcer duodenum, 02 were lymphoid hyperplasia Meckel's diverticulum, 02 were non-specific inflammatory mass of appendix and atrophic appendix and two were malignant cases ( 1 carcinoma of hypo pharynx and 1 carcinoma of ileo-cecal Junction).

Many similarly appearing oral lesions demand confirmation of diagnosis on both clinical and histopathologic grounds 6 . Microscopy plays a pivotal role here. Of the 73 samples that we studied; 14 cases (19\%) were sent by dental surgeons. Male and female were equally affected i.e., 07 cases each ( $50 \%$ each). Many of the biopsies were diagnosed as cysts of different types (like radicular cyst, dentegrous cyst, aneurismal bone cyst), fibrous epulis upper gingival mucosa, central giant cell granuloma, ossifying fibromas, osteomyelitis, pyogenic granulomas, and two malignant cases [one verrucous carcinoma, (75 years old male) and another well differentiated squamous cell carcinoma of tongue (again a 75 years old male).

The common breast lesions found in retrospective analysis of 3279 breast specimens received at the department of pathology, the Aga Khan University Hospital majority were infiltrating duct carcinoma $37 \%$, followed by fibro adenoma $16.95 \%$, fibrocystic change $13.96 \%$, mastitis $6.83 \%$ and duct ectasia $5.33 \%{ }^{7}$. In our study, out of a total of 73 cases, 05 were breast specimens (7\%). One was male and the rest were female. The common breast lesions included non-specific breast abscess, simple lipoma beast, galactocele with chronic non-specific inflammation, fibrocystic changes of breast and gynaecomastia in male. We observed no malignant cases, although it is commonly encountered in Pakistani females. Breast cancer occurs at a younger age group normally. The skin is a complex organ with many functions and three anatomic components: The epidermis with skin adnexa, melanocytic system, Dermis and subcutis or subcutaneous tissues ${ }^{9,10}$.

In countries with low socio-economic back ground including Pakistan, skin diseases prevail as much commonly as are other diseases. However, there is variation in the prevalence of these diseases not only within countries but also within a country ${ }^{8}$. The microscopic diagnosis is used by dermatologists to help in the appropriate management and clinical interventions of patients. Out of a total of 73 cases, 13 cases (18\%) were skin specimens. The male to female ratio was 8:5. Majority of the skin cases were benign lesions of the skin like lipoma, dermatofibroma, infiltrating cavernous haemangioma, squamous cell papilloma and pilomatrixoma right cervical area with some inflammatory lesion's chronic folliculitis, pilonidal sinus, non-specific inflammatory sinus and dermatitis herpetiformis. Enlargement of lymph nodes (Lymphadenopathy) is a common clinical problem and to determine the cause of nodal enlargement biopsies are undertaken to rule out benign and malignant cases ${ }^{11,12}$. In this study, we received 05 biopsies $(7 \%)$ to determine their histopathological spectrum. The male to female ratio was 1:4. Only one case showed malignant changes which was a poorly differentiated carcinoma (axillary lymph nodes) in 65 years old man. The rest were benign like reactive hyperplasia of lymph node, granulomatous lymphadenitis, central giant cell granuloma (maxillary L. node) and suppurative lymphadenitis. Male often encounter reproductive system problems which require biopsies to rule out any malignant pathology. In our study, we receive 03 biopsies (4\%) pertaining to this system ${ }^{16}$. One case was of impaired spermatogenesis, non-specific thickening of hydrocele and nodular hyperplasia of prostate. There are different types of thyroid disease, including hyperthyroidism, hypothyroidism, thyroiditis and Hashimoto's thyroiditis and Follicular neoplasms. Follicular neoplasms of the thyroid gland can both benign and malignant and include benign follicular adenoma and follicular carcinoma ${ }^{13}$. A follicular adenoma is a common neoplasm of the thyroid gland. The prevalence of thyroid adenoma was 3 and $4.3 \%$ in two autopsy series ${ }^{14,15}$. The 02 biopsies (3\%) that we received were follicular adenomas. On cytologic, sonographic, or clinical features a follicular carcinoma cannot be distinguished from a follicular adenoma. Therefore, a histologic confirmation is required for proper management.

This study, although, limited in many respects, like small number of biopsies and limited to a single center, can give an insight into the prevalence of different benign and malignant diseases related to histopathological specimens in the locality of Malakand division of Pakistan. Further large scale studies involving multiple centers and large cohort of population is needed to determine the 
Prevalence Of Different Diseases Based On Histopathological Features In Biopsies From Patients In Malakand Division....

prevalence of both benign and malignant diseases in the locality.

\section{CONCLUSION}

The study concluded that biopsies taken for different diseases are more prevalent to female reproductive system and the prevalence of different diseases is low in male as compared to female. Histopathological evaluation of biopsies is the gold standard for the early detection of lesions especially malignancies. Hence it helps in their timely diagnosis and correct management.

\section{ACKNOWLEDGMENTS}

We are thankful to Professor Dr. Anwar Ali and Anwar Clinical Laboratory (Anwar Hospital swat) for allowing us to access information.

\section{REFERENCES}

1. Heffner LJ, Schust DJ. The reproductive system at a glance. John Wiley \& Sons; 2010 Mar 29.

2. Thakur RY, Nikumbh DB, Swami SY. Clinico histopathological overview of git lesions in a rural hospital. Indian Journal of Pathology and Oncology. 2016 Apr;3(2):30514.

3. Stewart BW, Kleihues P. Breast cancer. World Cancer Report. World Health Organization. IARC Press, Lyon, France. 2003:188-97.

4. Mohandas KM. Tumours of the gastrointestinal tract. In: Shaha S.N. API textbook of Medicine 8th ed. Mumbai: The Association of Physicians of India; 2008:881.

5. Srivathsa SH. Scholars Journal of Dental Sciences (SJDS) ISSN 2394-496X (Online). Virchows Arch A Pathol Anat Histopathol. 1986;409(3):349-63.

6. Siddiqui MS, Kayani N, Pervez S, Aziz SA, Muzaffar S, Setna Z, Israr M, Hasan SH, Gill MS. Breast diseases: a histopathological analysis of 3279 cases at a tertiary care center in Pakistan. Journal of Pakistan Medical Association. 2003;53(3):94.

7. Adhikari RC, Shah M, Jha AK. Histopathological spectrum of skin diseases in a tertiary skin health and referral centre. Journal of Pathology of Nepal. 2019 Apr 3;9(1):1434-40.

8. Adhikari RC, Shah M, Jha AK. Histopathological spectrum of skin diseases in a tertiary skin health and referral centre. Journal of Pathology of Nepal. 2019 Apr
$3 ; 9(1): 1434-40$.

9. Montagna W. Structure and function of skin. Apocrine Glands. 1974;11:332-63.

10. Roy A, Kar R, Basu D, Badhe BA. Spectrum of histopathologic diagnosis of lymph node biopsies: A descriptive study from a tertiary care center in South India over $51 / 2$ years. Indian Journal of Pathology and Microbiology. 2013 Apr 1;56(2):103.

11. Kim LH, Peh SC, Chan KS, Chai SP. Pattern of lymph node pathology in a private pathology laboratory. The Malaysian journal of pathology. 1999 Dec 1;21(2):87-93.

12. McHenry CR, Phitayakorn R. Follicular adenoma and carcinoma of the thyroid gland. The oncologist. 2011 May; 16(5):585.

13. Silverberg SG, Vidone RA. Adenoma and carcinoma of the thyroid. Cancer. 1966 Aug;19(8):1053-62.

14. Silverberg SG, Vidone RA. Adenoma and carcinoma of the thyroid. Cancer. 1966 Aug;19(8):1053-62.

15. Gurung P, Jialal I. Physiology, male reproductive system StatPearls [Internet]. 2020 Mar 24.

CONFLICT OF INTEREST: Authors declare no conflict of interest

GRANT SUPPORT AND FINANCIAL DISCLOSURE: NIL

\section{AUTHOR'S CONTRIBUTION}

Following authors have made substantial contributions to the manuscript as under

Khan A: $\quad$ Main idea, Practical work (Data collection \& preparation)

Khattak M: Literature review, Discussion.

Saleem K: Statistical analysis, Literature search, Conclusion.

Khan SA: Critical review of manuscript.

Khan MA: Bibliography

Authors agree to be accountable for all aspects of the work in ensuring that questions related to the accuracy or integrity of any part of the work are appropriately investigated and resolved. 